\title{
"Hacia la luz de la civilización": afrodescendientes y nación en la literatura argentina (1851-1882)
}

\author{
"Towards the light of civilization": \\ afro-descendants and nation \\ in Argentine literature (1851-1882)
}

\section{Nathalia Guevara Jaramillo*}

Resumen: La dicotomía civilización/barbarie fue recurrente en la literatura argentina en el siglo xIx; en ella, los afrodescendientes tendieron a ser ubicados del lado negativo de la ecuación, es decir, como sujetos asociados a la barbarie. En este artículo se toma como eje esta dicotomía para explorar las representaciones de los descendientes de africanos en textos literarios representativos, con el objetivo de contrastar dichas representaciones, producidas por las élites, con la obra poética de algunos autores afrodescendientes de Buenos Aires. La lectura de ambos tipos de fuentes mostrará coincidencias y diferencias en la forma de situarse en el esquema de civilización y barbarie.

PalaBRas clave: Argentina, Literatura, Construcción de la nación, Afrodescendientes

ABSTRAC: The dichotomy civilization/barbarity was recurrent in 19th century Argentinian literature. People of African descent were usually placed in the negative side of the equation, that is, associated with barbarousness. In this paper this dichotomy is used as an axis for looking into representations of African descendants in representative literary works in order to set off in contrast these representations produced by the elites with the poetic works of several authors of African descent of Buenos Aires. Reading both kinds of historical sources makes it clear that they have coincidences and differences in their places in the scheme of civilization and barbarity.

Key words: Argentina, Literature, Nation building, Afro-descendants.

Recibido: 20 de septiembre de 2017 Aceptado: 29 de noviembre de 2017

unam. Programa de Becas Posdoctorales. Becaria del Instituto de Investigaciones Sociales, asesorada por la doctora Natividad Gutiérrez Chong (nataguevara@yahoo.com). 


\section{INTRODUCCIÓN}

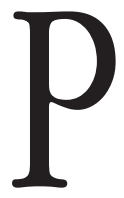

ara Juan María Gutiérrez, reconocido como el primer crítico literario argentino, la literatura y la patria iban de la mano. Gutiérrez, que formó parte del grupo de escritores del Salón Literario de Buenos Aires, fundado en 1837, consideraba que la literatura tenía una responsabilidad en la conservación de la memoria y que sus géneros se movían a la par con los momentos clave de la historia patria. En este sentido, la poesía y la literatura cumplían una clara función política (Amante 2003: 167). Así, la literatura nacional era inventada a la par con la nación a la cual representaba. En las páginas siguientes me referiré de manera general a la forma como algunos autores de las élites argentinas representaron y situaron a los descendientes de africanos en la oposición entre civilización y barbarie, considerando como referencia diversos cuentos y novelas de la época; luego, retomaré varias obras poéticas de autores afrodescendientes para explorar sus posturas con respecto a dicha oposición. Al contrastar las fuentes literarias producidas por miembros de las élites y de sectores sociales subalternos, planteo que es posible dar cuenta de sus diversas formas de representar la nación, así como de sus intentos discursivos por situarse en ella.

\section{CIVILIZACIÓN, BARBARIE Y AFRODESCENDIENTES \\ EN LA ÉPOCA DE FACUNDO}

La relación de los afrodescendientes con Juan Manuel de Rosas, gobernador de la provincia de Buenos Aires desde 1829 hasta 1852, con apenas una pausa entre 1832 y 1835, fue un elemento clave en las representaciones construidas por las élites argentinas en torno a este sector de la población. De acuerdo con autores como Pilar González Bernaldo (2000) y Gabriel Di Meglio (2008: 72), una relación clientelista entre ambas partes habría garantizado la lealtad de las asociaciones africanas al régimen, a cambio de beneficios económicos, sociales o legislativos. Esta posición 
ha sido criticada por Ricardo Salvatore (2007), quien la considera elitista y estima que la cercanía de los afrodescendientes al rosismo debe ser leída a partir de su deseo de defender los avances logrados en torno a la abolición de la esclavitud, sin perder de vista su agencia, evidenciada en numerosos registros judiciales de la época (57-80). En todo caso, la cercanía entre afrodescendientes y rosismo generó el rechazo de los unitarios y fue plasmada en varias obras literarias producidas a partir de la década de 1830 .

El régimen de Rosas buscaba eliminar el disenso con la ayuda de la Mazorca, un cuerpo parapolicial que perseguía a quienes identificaba como opositores. Para muchos de ellos, no quedó más remedio que el exilio. Tal fue la suerte de varios de los escritores del Salón Literario de Buenos Aires, que luego serían identificados como la Generación del 37, entre quienes se encontraban Esteban Echeverría, Juan Bautista Alberdi y Domingo Faustino Sarmiento. Así, Facundo o Civilización y Barbarie, quizá la obra más representativa de este esquema de pensamiento dual sobre la sociedad argentina, nació mientras Sarmiento se encontraba exiliado en Chile. El relato está articulado en torno a la vida de Juan Facundo Quiroga, caudillo de La Rioja. Mediante la figura de Facundo, el autor retrata la vida argentina, el paisaje del país y los pueblos que lo habitan.

En el esquema interpretativo de Facundo había implícita una forma de concebir el movimiento de la historia. La lucha entre la civilización y la barbarie, según Elias Palti, delimitaba "dos universos de sentido opuestos", ubicados en planos espacio-temporales distintos. Civilización y barbarie no eran dos categorías aisladas, sino que una era la contracara de la otra. Si la civilización era lineal y permitía el progreso, la barbarie era estática e implicaba el estancamiento; a su vez, la nación era la síntesis entre ambas dimensiones. Sarmiento se proponía, entonces, entender cómo la barbarie, que representaba una negación de la historia, había adquirido un carácter histórico con la llegada de Rosas al poder (Palti 2009: 57-58). De esta manera, el esquema de civilización y barbarie, así como el lugar que los grupos humanos ocupaban en él, se convirtieron en formas hegemónicas de pensar la nación argentina. 
Sarmiento explicaba que los descendientes de africanos eran una parte clave de las "bases duraderas" de Rosas para consolidar su poder en Buenos Aires. La única cualidad que Sarmiento destacaba de la "raza salvaje" africana era su capacidad guerrera, que brindó una "base indestructible" al poder del gobernador. "Felizmente - señalaba el autor- las continuas guerras han exterminado ya la parte masculina de esta población" (1999: 309). La vinculación de hombres de ascendencia africana a ejércitos y milicias desde la época de las invasiones inglesas no implicó su inclusión en el relato de una nación fundada, al menos en lo imaginario, en guerras en las cuales ellos mismos habían participado. De esta manera, según Lea Geler, al representar a los afrodescendientes como soldados que daban su vida por la patria, Sarmiento empezaba a enunciar la "desaparición" de este sector de la población que, sin embargo, no tenía una importancia menor en la sociedad de la época (2008: 37). Hay que destacar que a finales del periodo virreinal, cerca de un tercio de los habitantes de Buenos Aires eran afrodescendientes. De acuerdo con conteos realizados en 1836 y 1838, en aquel entonces los afrodescendientes alcanzaban el 26\% de la población de Buenos Aires (Andrews 1989: 81). Pese a que en 1813 un decreto había iniciado el proceso de abolición gradual de la esclavitud, ésta permanecía vigente; a su vez, la trata de esclavos había sido interrumpida y reactivada varias veces desde la primera proscripción, ocurrida en 1812. Por ello, los esclavizados y libres de ascendencia africana desempeñaban oficios muy diversos y seguían siendo actores clave en la economía de la época. ${ }^{1}$ La afirmación de Sarmiento sobre la desaparición de los afrodescendientes, que parece wishful thinking en el contexto social y político de la década de 1840, se convertiría en un proyecto de nación a lo largo del siglo XIX. Facundo, entonces, contribuyó a institucionalizar lo que Solo-

1 Sobre los decretos de abolición de la trata y de reclutamiento de esclavizados, véase Crespi 2010. En cuanto a la permanencia de la trata y el incumplimiento de la abolición gradual, véase Rosal 2009. Los testimonios visuales de la época dan cuenta de la importante presencia afrodescendiente en la ciudad de Buenos Aires; al respecto véanse, también, las ilustraciones de Emeric Essex Vidal (Picturesque Ilustrations of Buenos Ayres and Montevideo, Londres, 1820) y de Hipólito Bacle (Trages y costumbres de la provincia de Buenos Aires, Litografía de Bacle y C. ${ }^{a}$ Buenos Aires, 1833). 
mianski llama un "genocidio discursivo" (2015: 107, 109), en el cual estas presencias subalternas fueron silenciadas y mostradas como elementos en vía de extinción.

El Matadero, un relato escrito por Esteban Echeverría, es un buen ejemplo de los recursos literarios utilizados para enunciar el sistema clasificatorio que ubicaba del lado de la barbarie a los federalistas y a los afrodescendientes. La narración fue escrita hacia 1840 pero se publicó de manera póstuma en 1871. La historia transcurre en Buenos Aires, en un año no precisado de la década de 1830. Luego de unas fuertes lluvias, la ciudad se había inundado y se había cortado el suministro de carne al matadero. Cuando por fin se reanudó la entrada de reses, una "multitud de negras rebusconas de achuras, como los caranchos de presa, se desbandaron por la ciudad como otras tantas harpías prontas a devorar cuanto hallaran comible. Las gaviotas y los perros, inseparables rivales suyos en el matadero, emigraron en busca de alimento animal" (1874: 217). ${ }^{2}$ Entre los asistentes a este evento, destacaban las negras "achuradoras, cuya fealdad trasuntaba las harpías de la fábula”, quienes competían con los perros para obtener una presa. Los matarifes, federalistas y miembros de la plebe porteña, carneaban novillos del mismo modo que mataban unitarios. El matadero era, entonces, una pequeña réplica del régimen rosista (Echeverría 1874: 225-228).

La violenta pugna política entre federales y unitarios, así como la supuesta animalidad de los descendientes de africanos, fueron también abordadas en Amalia, la única novela escrita por José Mármol. Publicada entre 1851 y 1852 por entregas y luego complementada por el autor en 1855, Amalia narraba la historia de amor entre una joven viuda tucumana, que da nombre al libro, y Eduardo Belgrano, sobrino de Manuel Belgrano, prócer de la independencia. La novela plantea una historia amorosa ambientada en la pugna entre la civilización y la barbarie, en la cual los afrodescendientes, asociados al rosismo, aparecen en el lado negativo de la oposición.

2 Las achuras eran las vísceras de los animales, mientras que los caranchos son aves silvestres. 
De acuerdo con Mármol (1877), la "raza africana" atacaba la libertad que la patria le había concedido de manera generosa con la ley de libertad de vientres de 1813. Lo que el autor no tenía en cuenta es que la persistencia de la esclavitud en el momento en el que se enmarcaba su narración, el año de 1840, demostraba la poca efectividad de dicha ley. La raza, en el discurso de Mármol, no se refería sólo a una cuestión fenotípica. Sobre este concepto, Pérez Vejo explica que en Occidente existía una creencia en que las características morales e intelectuales se transmitían de manera hereditaria, la cual se reforzó en el siglo XIX con base en ideas que atribuían la supuesta desigualdad entre razas humanas a distintos estadios evolutivos. La raza, entonces, era percibida como una suma de características físicas, morales y sociales (2015: 90-93).

Según Mármol, tales cualidades morales se evidenciaban en "los instintos perversos que se revelaron en aquella clase de la sociedad" durante el rosismo. De acuerdo con el relato, los descendientes de africanos poseían una propensión a "ejecutar el mal" y a desarrollar defectos tales como la calumnia, la ingratitud o la venganza, los cuales los habían llevado a revelar su odio "sincero y profundo" hacia las "clases honestas y acomodadas de la ciudad". El dictador, decía Mármol, "lisonjeó sus instintos, estimuló sentimientos de vanidad hasta entonces desconocidos para esta clase, que ocupaba por su condición y por su misma naturaleza el último escalón de la gradería social" (Mármol: I, 211-212). De esta manera, la asociación de Rosas con sectores afrodescendientes demostraba la barbarie de su régimen e impedía el progreso de la sociedad, pues se valía de los sujetos que representaban el estadio más bajo de la línea evolutiva de las razas humanas. En Amalia, la presencia de los afrodescendientes en la esfera pública y privada de Rosas, la manera como éste los usaba en la máquina represiva paraoficial y el apoyo de muchos de ellos al régimen, parecían evidenciar su falta de agencia racional y el peligro que representaba permitirles acceder al poder. El igualitarismo que promovía el rosismo al afirmar que "en la Federación no hay negros ni blancos, todos somos iguales" (277), planteaba un peligro en la medida en que daba a los personajes afrodescendientes la posibilidad de actuar al margen de las jerarquías sociales existentes. 
A lo largo de la novela, los afrodescendientes son descritos mediante rasgos exagerados y grotescos que rayan en la animalidad, tal es el caso del Padre Viguá, un bufón de Rosas, en cuyas "facciones informes estaba pintada la degeneración de la inteligencia humana, y el sello de la imbecilidad" (48). En otro pasaje de la novela, las mujeres negras que rodeaban a la familia de Rosas contrastaban con Florencia Dupasquier, una joven elegante, blanca y mitad francesa. Para visitar a María Josefa Ezcurra, cuñada de Rosas, Florencia había tenido que taparse la cara con su pañuelo perfumado y así "abrirse camino por entre una multitud de negras, de mulatas, de chinas, de patos, de gallinas, de cuanto animal ha criado Dios" (80). En la narración, convertir en grotescos los cuerpos y sus acciones es un recurso literario y político. ${ }^{3}$

Cuando Daniel, amigo de Eduardo y primo de Amalia, le pide a ella que se deshaga de sus criados para evitar una posible delación, le explica que "Sólo hay en la clase baja una excepción, y son los mulatos", puesto que, debido a su mezcla racial, eran propensos a dignificarse e identificarse con los unitarios blancos (22). En coincidencia con las ideas sobre las razas a las cuales me he referido antes, el blanqueamiento racial implicaría la adopción de hábitos y posturas más cercanos a la civilización, representada por los unitarios. Blanquear la piel, entonces, era también blanquear las ideas. La novela de Mármol no parece plantear la posibilidad de que el amor disuelva las fracturas raciales que dividían a la sociedad argentina de la época. Los protagonistas, ambos pertenecientes a las élites, son perseguidos a lo largo del relato y su amor, al final, resulta impedido por los representantes de la barbarie federalista. ${ }^{4}$

Amalia fue un modelo para otras novelas del llamado "ciclo de la tiranía", un momento que Hebe Beatriz Molina ubica entre 1852 y 1861, en el cual se publicaron diversos textos literarios con la finalidad explíita de rememorar el rosismo. Con pocas excepciones, de acuerdo con Moli-

3 Una interpretación que también señala la animalidad y la forma grotesca de describir a las mujeres afrodescendientes se encuentra en Geler 2008: 50-52.

4 Con respecto a la relación entre la novela romántica y la nación en América Latina, véase Sommer 2004. 
na, las novelas de la época tuvieron en común la presencia de un narrador acorde a las ideas políticas del autor, quien pretendía convencer al lector de la tiranía del gobierno de Rosas. Asimismo, estas novelas buscaban prevenir contra nuevos tiranos, dividían a sus personajes en bandos irreconciliables en favor y en contra de Rosas, narraban historias de amor condicionadas por la participación del protagonista masculino en acciones contra el tirano e incluían anotaciones históricas (Molina 2011: 82-84, 288-289). Aunque en buena parte de estas novelas los esclavizados y afrodescendientes no parecen haber jugado un papel tan determinante como en Amalia, ${ }^{5}$ las formas en que son representados retoman varios de los temas señalados antes, tales como la animalidad, la falta de agencia racional y la delación.

Un ejemplo de ello es Los misterios del Plata, de Juana Manso (1846), una novela anterior a Amalia. ${ }^{6}$ El relato se sitúa en 1838 y cuenta la huida de Valentín Alsina (identificado con el seudónimo de Avellaneda) y su familia, perseguidos por el régimen rosista. En su viaje hacia Corrientes por el río Paraná, el barco donde Avellaneda viaja es interceptado y él es capturado y juzgado por unitario. Miguel y Simón, gauchos que sirven al gobernador rosista, se ven cuestionados por las virtudes del prisionero quien, hasta entonces, se les ha presentado como un salvaje y traidor, pero, en realidad, defiende el perdón y la justicia. Los dos gauchos se convierten en amigos por su decisión de salvar a Avellaneda y a su familia, pero fracasan en el intento. Así, Avellaneda es apresado de nuevo y llevado a Buenos Aires. En la narración de Manso, los esclavizados y los bufones negros vuelven a aparecer rodeando a Rosas y a los mazorqueros. Al gobernador se le presenta seguido por "dos grandes mulatos, asquerosos y sucios, casi desnudos respondiendo a los nombres de Biguán y el otro al de Mulato Gobernador! Estos dos infelices, medio idiotas, medio locos, son las víctimas de todos los caprichos y barbaridades de Rosas, son sus graciosos particulares" (Manso 1899: 107-109). De Salomón, el jefe de la Mazorca, la autora

5 Al respecto, véase el apéndice II del libro antes citado de Hebe Beatriz Molina, en el cual la autora presenta fichas temáticas de las novelas que analizó.

6 Aunque la novela se publicó en 1846, la edición utilizada es de 1899 y se le agregaron varias páginas al final del manuscrito original. 
dice que desciende de una indígena y un mulato, mientras que a Parras, un temible asesino, lo describe como "un mulato colosal [...] peón de matadero, borracho y cuchillero" (136-137).

Cuando Avellaneda llega a la ciudad, los rosistas convierten su ejecución en una fiesta popular. Los mazorqueros son seguidos por "el populacho, la escoria de la sociedad de Buenos Aires. Mujeres, blancas y negras, mulatas y chinas, viejos, muchachos y pampas", quienes vociferan y apedrean cristales y faroles (170). Los candombes de negros son convocados para la celebración pues, según la autora, Rosas los usaba para hacer algarabía en la ciudad y, así, "aturdir y levantar a las masas para que sirvan a su capricho [... ] y como de estas ocasiones, solo resulta, tumulto, bulla y desorden, nadie piensa y él hace lo que quiere o le conviene" (123-124). En una sección agregada posteriormente al manuscrito por parte del editor, Adelaida, la esposa de Avellaneda, decide valerse de su fiel nodriza negra como espía para salvar a su esposo preso. El narrador explica que, en el régimen rosista,

[...] los negros descendientes de los cargamentos de esclavos africanos vendidos durante el coloniaje, desempeñan un papel prominente, porque constituyendo el elemento casi exclusivo del servicio porteño son los que están en condiciones de transmitir y delatar [...]. Los negros que no están colocados en casas particulares viven en comunidades, que llaman pueblos, situados en los barrios de extramuros, conservando sus usos y costumbres africanas [...]. Estos pueblos de negros adoran a Rosas que, a la verdad, les dispensa toda clase de favores y les acuerda su más ilimitada confianza, en lo que no se engaña, pues se sabe que es la fidelidad una de las características de la raza africana. El pueblo bajo, compuesto en buena parte por negros y mulatos, está conforme con Rosas como lo estuvo en la Roma de los césares con Claudio, con Nerón o con Calígula (207-209).

Incluso cuando las narraciones destacan la fidelidad de los personajes afrodescendientes, éstos son representados como colaboradores de la tiranía o seres carentes de agencia. Por ejemplo, en Camila o la virtud triunfante, de Estanislao del Campo (1856), la relación entre esclavizados y rosistas se presenta mediante la figura de Manuel, un criado fiel a Blas de Aguilar; este último, un antiguo mazorquero, arruina a Camila cuando ella 
se niega a sus pretensiones amorosas (Del Campo, 1856). En El Prisionero de Santos Lugares, de Federico Barbará (1857), el negro Tomás Patria y su amo, Jorge, son encarcelados por un federalista celoso con quien Jorge disputa el amor de Carolina. Tomás contribuye en la fuga de Jorge, quien logra casarse con Carolina en un pueblo de Uruguay. Años después, Tomás y Jorge participarán en la batalla de Caseros, en la cual fue derrotado Rosas, y Jorge perdonará la vida a su enemigo. En la cárcel, el deseo de servicio de Tomás lo motiva a tolerar el encierro. Luego, en su escape a Uruguay, Tomás rescata de un naufragio a la madre de Carolina, mientras que Jorge hace lo mismo con su amada. Sin tener quien la rescate, una criada negra muere en el incidente. ${ }^{7}$

Por su parte, las obras literarias ubicadas en contextos políticos, temporales y geográficos distintos al del rosismo parecen revelar imágenes más benévolas de los afrodescendientes, las cuales no carecen de problemas. En el Tío Antonio (1880), un cuento de Eduarda Mansilla de García, el protagonista, un esclavizado con una tendencia natural a la ociosidad y una instintiva repugnancia al trabajo, logra redimirse gracias a las enseñanzas de su buen amo, Miguel. La historia ocurre en la época de las guerras de independencia y Antonio, en parte gracias a su contacto con peones blancos, se vuelve patriota, aunque "con esa reserva y esa pasividad inherentes al esclavo". La fidelidad lo lleva a sacrificarse de diversas maneras: luego del fusilamiento de Miguel, mantiene a su esposa e hijos, pero pudiendo ser libre, decide quedarse al lado de su ama y, luego, ser vendido para que ella y sus hijos regresen a su natal Cádiz. Hasta la vejez, Antonio permanece al servicio de su ama, Mercedes, pues "había nacido para vivir en beneficio de los demás" (Mansilla 1880: 162-174).

Otras narraciones, como La familia del comendador, de Juana Manso (1854), ambientada en Río de Janeiro, o El ángel caído (1865) y Peregrinaciones de un alma triste (1877), ambas de Juana Manuela Gorriti,

Javier de Navascués analiza esta novela, junto con los relatos de Juana Manso y de Juana Manuela Gorriti a los que me refiero más adelante, e identifica en ellas formas estereotipadas de representar a los esclavizados como criados fieles y soldados valientes. Al respecto, véase Folger y Gutiérrez 2017: 171-194. 
ubicadas en Lima, también exploran temas como la fidelidad de los afrodescendientes, su lujuria y su posibilidad de mejora mediante el blanqueamiento. En estas obras, los afrodescendientes aparecen representados mediante lo que Navascués llama "estereotipos subalternos", cualidades inherentes que los proyectan como seres dependientes del poder de los blancos y carentes de agencia propia (2017: 171-194).

El discurso literario fue, entonces, un espacio donde se construyeron las ideas hegemónicas sobre la diversidad racial y su papel en el progreso de la nación. Tales ideas, expresadas en novelas y cuentos con una fuerte carga políica, sustentaron la creación de representaciones que reafirmaban jerarquías raciales, morales y sociales, y que planteaban la dificultad de la integración de los afrodescendientes al país, lo cual hacía deseable su desaparición como vía hacia la civilización. Sin embargo, la literatura no fue sólo un asunto de las élites, pues con la caída del rosismo, la prensa ganó una gran popularidad entre otros sectores de la sociedad, que vieron en ella una posibilidad inédita de expresarse por escrito. La literatura escrita por autores afrodescendientes, en buena parte publicada en periódicos, es un ejemplo de ello.

\section{FOMENTAR EL "AMOR A LAS LETRAS": \\ POESÍA AFRODESCENDIENTE EN BUENOS AIRES}

Mientras las élites enunciaban la desaparición de los afrodescendientes y la necesidad de civilizar el país con migrantes europeos, la comunidad afrodescendiente de Buenos Aires mostraba una gran vitalidad, registrada en sus periódicos. Según George Reid Andrews, después de 1858 habrían existido al menos 15 periódicos afrodescendientes con frecuencia semanal y bisemanal. Aunque algunos de ellos tuvieron una vida corta, a finales de la década de 1870 hubo un auge del periodismo afrodescendiente y se crearon los periódicos de más duración (Andrews 1989: 212). Durante el rosismo, la libertad de imprenta fue restringida como forma de reducir la opinión a la propaganda oficial del gobierno (González 2000: 168-169). Rosas llegó a tener un gran control sobre las publicaciones y la legislación 
que le permitía aprobarlas se mantuvo hasta su caída. Sin embargo, en los años posteriores, la prensa porteña creció de manera considerable, al punto de que, según Hilda Sábato, se producía un ejemplar de periódico por cada cuatro habitantes de la ciudad. Mientras el número de personas alfabetizadas iba en aumento, la prensa se convertía en un elemento central de la vida política, así como en una estrategia para tener voz y opinión pública (2010: 99-101).

Geler, quien ha estudiado a profundidad la prensa afrodescendiente de Buenos Aires a finales del siglo XIX, plantea que ésta funcionaba como un instrumento educativo que acercaba a los afrodescendientes al progreso, a la vez que moralizaba, disciplinaba e inducía a ingresar al mercado de trabajo en formación y difundía normas de civilidad de los sectores hegemónicos. La autora también llama la atención sobre el estatus de estos intelectuales subalternos dentro de su comunidad, así como sobre su posición privilegiada para crear un discurso político de cambio en un contexto de dominación o para actuar como mediadores con capacidad de imponer determinadas visiones del mundo (2008b: 171-185).

Uno de los periódicos afroporteños de más duración fue La Broma, activo entre 1877 y 1882. Según Andrews, este periódico surgió como un medio de expresión de la élite afrodescendiente porteña pero, con el tiempo y las divisiones comunitarias, empezó a dirigirse también a sectores obreros (223-226). La Broma difundía artículos y contribuciones diversas, tales como editoriales políticos, notas sociales o reediciones. Destacados escritores afrodescendientes, como Mateo Elejalde o Froilán Bello, publicaban allí poemas suyos con bastante asiduidad.

La poesía de autores afrodescendientes es un testimonio interesante de su acomodamiento a los cánones dominantes en la producción literaria de la época, así como de sus reacciones ante las representaciones hegemónicas difundidas en la literatura de las élites. El lenguaje poético permitía hacer críticas al poder sin necesariamente oponerse a él y sin separarse de los valores considerados como civilizados sino, por el contrario, adscribiéndose a ellos. En otras palabras, permitía hablarle al poder en su propio lenguaje, con base en sus cánones y con una franqueza quizá 
más difícil de lograr mediante la prosa. Como lo señala Marvin Lewis, los poetas afroargentinos también incorporaron temas propios del romanticismo, tales como el amor, la libertad y la justicia social; no obstante, escribieron como "proscritos", cuyas preocupaciones literarias cuestionaban la dominación de la cultura mayoritaria y enunciaban un "exilio interno" (1996: 24-25, 50). De acuerdo con el autor, la "etnicidad" habría sido un componente primario de la obra de los poetas afroporteños del siglo XIX (131). Sin embargo, son relativamente pocos los poemas que se refirieron de manera explícita a la situación de los afrodescendientes; asimismo, la adopción de temas y cánones del romanticismo sugiere que dicha "etnicidad" no fue su principal preocupación. Al igual que los hombres de las élites, estos escritores concebían la historia como un movimiento hacia delante, en busca del progreso. La literatura, la poesía y el periodismo eran una esperanza de avanzar en este movimiento. Así, aun si escribían desde el "exilio interno" y la marginación, sus intentos por transitar hacia la civilización seguían siendo visibles.

De acuerdo con las columnas de La Broma, los poetas eran percibidos como representantes de una nueva generación de jóvenes que, aunque carecían de reconocimiento en la sociedad en su conjunto, ejemplificaban el avance de la comunidad afrodescendiente. Un editorial se refería a los bazares realizados por las hermandades de la comunidad, en los cuales se realizaban actividades musicales y literarias en las que participaban los jóvenes. Hacía algún tiempo, durante un bazar de la sociedad La Protectora, las obras musicales y el certamen literario habían dejado una buena impresión porque "se ignoraba que entre nosotros hubiera escritores, literatos y poetas". Según la nota, los participantes habían recibido "ardientes felicitaciones de personas altamente reputadas en el ramo de las letras". La hermandad del Rosario realizaría un bazar pronto, el cual contaría con una conferencia literaria en la que participarían Mateo Elejalde, Ernesto Mendizábal y Casildo Thompson, entre otros jóvenes de la comunidad reconocidos por sus habilidades poéticas. Según el periódico, significaba una muestra de que "cada día se acentúa más entre nosotros, la idea de la sociabilidad y de la ilustración" ("El bazar de la Hermandad del 
Rosario". La Broma. 23 jul. 1881: 1). ${ }^{8}$ Como éste, diversos artículos de esta publicación dan cuenta de una búsqueda de reconocimiento por parte de los sectores ilustrados de la sociedad porteña, así como de una valoración positiva de las artes como medio para alcanzarlo.

Algunas obras poéticas fueron dedicadas a la situación concreta de los afrodescendientes en Buenos Aires. El poema "La Redención", de Mateo Elejalde, fue publicado en este periódico en 1881 y reafirmaba la importancia de la educación como estrategia de progreso:

Ya sonó la hora anunciada / En que una raza oprimida / Empieza á entrar en la vida/De sublime redención; / Por fin... la pálida noche / Que nuestro cielo cubría / Nos anuncia un bello día / De dulce resurrección. (...) Adelante, sí! Adelante / Cada vez con más constancia / Odio eterno á la ignorancia / Amor á la educación! / A la educación divina / Inestinguible lumbrera / Y celeste mensagera / De sublime redención.(La Broma. 3 de febrero de 1881: 2).

Según el poema, la "raza oprimida" entraba "en la vida", lo cual implicaba que estaba abandonando algo ocurrido en el pasado. ¿A qué se refería Elejalde con "la pálida noche/Que nuestro cielo cubría"? ¿Qué entendía por "ignorancia"? Es posible que este pasado "pálido" hiciera alusión a la esclavitud y al apoyo que muchos esclavizados y libres habían dado al régimen de Rosas, así como a la permanencia de manifestaciones artísticas que las asociaciones africanas habían mantenido vivas durante el rosismo, tales como la música y las danzas. Al respecto, Andrews cita un discurso de prensa sobre la necesidad de trasladar los candombes, bailes de origen africano, a una esfera privada. La nota advertía sobre la importancia de que los jóvenes tocaran otros instrumentos musicales diferentes a los "antiguos y patéticos tambores que ahora sirven sólo como el único recordatorio de las costumbres venerables pero corruptas de hace mucho tiempo" (195). En el mismo tono, un editorial de La Broma de 1881 celebraba que "Ya empezamos a desprendernos por completo de nuestros viejos hábitos y de nuestras costumbres tradicionales que aún conservábamos - has- 
ta há poco- como un triste rezago de nuestra negra ignorancia, como una fatal memoria del doloroso pasado" ("Nuestro porvenir". La Broma. 7 de julio de 1881: 1). El momento en el que Elejalde escribe el poema parece ser una nueva época, en la cual la educación salvaría a la comunidad afrodescendiente de su pasado, para introducirlo en el mundo de la civilización que perseguía el proyecto de nación argentino. Lewis lee este poema como un "llamado a las armas" y un "ejercicio de concientización" (30); sin embargo, a mi parecer, el cambio al que se refiere es un abandono de los referentes culturales africanos, considerados como lejanos a la civilización. En este sentido, aun cuando en el poema hay una reivindicación de los afrodescendientes como comunidad, esto no implica su adhesión a una identidad étnica como descendientes de africanos.

En la misma edición del periódico La Broma donde se publicó este poema, un artículo exaltaba el progreso de la comunidad afrodescendiente, evidenciado en el interés de los jóvenes por escribir en periódicos y folletos pues éstos habían merecido "los honrosos conceptos de parte de personas competentes e ilustradas". Los mejores ejemplos de este movimiento eran jóvenes como el propio Mateo Elejalde y otros poetas y escritores que marchaban "al frente de todo movimiento que importe un adelanto para la sociedad". "A este paso - decía la nota- las preocupaciones que algunos seres mezquinos alimentan respecto á nuestra raza, tienen que ser vencidas, porque no hay ejemplo en el mundo, de jóvenes como los nuestros: pobres, sin gran preparación y entregados a trabajos rudos que no dejan tiempo para meditar". Al respecto, otra nota hablaba del estado "halagador" de "nuestra sociedad". Hasta hacía poco, decía, "nuestros hombres permanecían fríos e indiferentes"; sin embargo, en la actualidad parecía que se fortalecían con el "impulso de la luz de la civilización que les marca con sus destellos de oro la luz del trabajo". De acuerdo con el artículo, un "movimiento general" venía ocurriendo en esta comunidad desde hacía unos diez años. Una nueva generación se levantaba "con espíritu retemplado al vigor del regazo tierno de la patria madre" ("Actualidad". La Broma. 22 de agosto de 1878: 1). ${ }^{10}$ Una de las

10 Las cursivas son mías. 
formas de alcanzar esta "luz" asociada con el progreso y la civilización era la palabra y, en general, el "amor a las letras" ("Ideas benéficas". La Broma. 2 de octubre de 1879: 1).

Así, la dicotomía entre civilización y barbarie seguía influenciando la forma en que estos escritores pensaban su lugar en la sociedad. El progreso y el atraso, nociones frecuentes en sus discursos, entrañaban asimismo una visión hegemónica de la historia. El progreso era visto como un movimiento hacia delante, el cual parecía expresar un deseo de no mirar hacia el pasado. A mi juicio, en estos discursos, los escritores concebían su propio papel en la sociedad y en la historia adhiriéndose a las representaciones hegemónicas promovidas por las élites intelectuales y políticas argentinas. En este sentido, dichos testimonios literarios subalternos remiten al concepto de hegemonía de Gramsci, que se refiere al poder como una relación compleja que, para poder mantenerse de manera duradera, requiere del consentimiento de los subordinados. Para Kate Crehan, quien ha analizado la obra de Gramsci desde una perspectiva antropológica, la visión del mundo de los subalternos se crea en el marco de sus condiciones de subordinación y de unas concepciones hegemónicas que reflejan la visión del mundo desde los sectores dominantes (2002: 137-138). ${ }^{11}$

Con la caída del rosismo, la "patria madre", que recibía a los afrodescendientes en su regazo, había aprobado una nueva constitución que abolía por completo la esclavitud y las prerrogativas de "sangre o de nacimiento". ${ }^{12}$ Sin embargo, la igualdad estaba lejos de lograrse, como lo muestran algunos poemas y artículos de prensa escritos por autores afrodescendientes. La Broma no siempre presentó visiones similares a las del poema de Elejalde y los artículos de prensa citados antes. En otros casos, la publicación también sirvió para criticar de manera abierta la discriminación. Un artículo de marzo de 1880 se quejaba sobre el hecho de que a los descendientes de africanos se les considerara ciudadanos sólo en épocas electorales, que se les negaran sus derechos de "hombres libres" y que, por tanto, la ley que pregonaba la igualdad no se realizara en la práctica.

11 Véase Geler 2008b: 182, quien realiza una interpretación similar.

12 Véase Constituciones Argentinas. Compilación y análisis doctrinario, 2015: 280. 
"Nuestra raza - afirmaba la nota-siempre es despreciada, sin acordarse de que ella ha contribuido con su sangre á conquistar la independencia y libertar de que hoy goza este país" ("Los candidatos y los negros". La Broma. 21 de marzo de 1880: 1-2). Otra nota se lamentaba de la carencia de representación política afrodescendiente y de que, año con año, el tiempo pasara sin que ninguno de los suyos obtuviera "un puesto concedido por la ley y la democracia" "Cuestión social". La Broma. 11 de diciembre de 1879: 1). En un número de 1882, una contribución firmada por Román I. López, titulada "Los desheredados", abordaba el problema de la discriminación de manera abierta:

¿Por qué la sociedad con infundada / Y punible soberbia / Al ser que nace con la tez oscura / Abomina y desprecia? / ¿Por qué una raza con desdén injusto / A la otra considera? / ¿Es deshonor, algún delito acaso; / Poseer la faz morena? / Yo no miro el color de los que encuentro / A mi paso en la tierra / Examino tan solo sus acciones / Las que el alma reflejan. / iCuántos pisan la vasta superficie / De este hermoso planeta / Que el rostro tienen de blancura nítida / Y la conciencia negra! ("Los desheredados". La Broma. 28 de julio de 1882: 3).

En ocasiones, los versos fueron una manera de hacer críticas a situaciones concretas de racismo. Una de ellas fue la prohibición de entrada al teatro de propiedad de un empresario extranjero, la cual generó el repudio de los periodistas y ameritó algunos versos firmados por Restituta (Esposa de Ateirra):

Dicen que "Beodo" el del circo / Que le llaman Nacional, / No deja entrar á las "negras" / Porque no saben bailar. / Dicen también que a la chusma / También le es prohibido entrar / Pero entran "gabiones" finos / Que estudian para robar.

(...) Se arma cada trifulca / Como una gran tempestad / Y trompis y puñaladas / De gratis allí se dan. / (...) Así son los bochinches / Del gran Circo Nacional / iiiY no dejan entrar "negras" / Porque no saben bailar!!!

El artículo que precedía los versos manifestaba un profundo malestar con esta medida y criticaba el hecho de que se le permitiera la entrada a 
bandidos de piel blanca, mientras se le negaba a quienes tenían el "rostro oscuro". Según la nota , "ninguno de nuestros hermanos cambiaría el humilde empleo de 'sirviente' por el más lucrativo del de esos viles traficantes de carne bumana" ("El circo nacional". La Broma. 24 de eneero de 1880: 1). ${ }^{13}$ La mitad del número se dedicó a discutir este caso. La tensión que generó el acto discriminatorio ameritó la asociación de los europeos con los "traficantes de carne humana", es decir, los comerciantes de esclavos. De esta manera, los periodistas planteaban una inversión de los lugares que se le asignaban a blancos y negros en el esquema de la civilización y la barbarie.

Una de las voces más críticas dentro de los poetas afroargentinos fue la de Casildo Thompson (1856-1928), quien en su poema "Canto al África" (1878) también cuestionaba e invertía la forma en que los africanos y afrodescendientes habían sido representados desde la perspectiva de las élites blancas. Aquí, la "raza africana" adquiría cualidades encomiables y era descrita como una "raza que es mártir por su historia". El poema continuaba: "Raza digna de gloria / Porque es noble y activa / Como el león que entre la selva mora, / Y que en acerba hora / Arrastróla al abismo de la infamia, / Y sin temblar, la fratricida mano / De un bárbaro Caín, cruel inbumano". El poema de Thompson presenta una inversión de la dicotomía civilización y barbarie. En él, los africanos son dignificados por ser nobles y activos, así como mártires de una cruel historia de trata esclava. Desde esta perspectiva, los bárbaros eran los modelos civilizatorios de la nación argentina, es decir, los europeos. El continente africano también era reivindicado como una "tierra virgen" y patria de los negros; asimismo, era equiparado a una mujer profanada por la codicia de los tratantes.

¿Sabéis cómo se llama / Esa tierra divina y bendecida, / Esa joya que al mundo Dios legara, / Esa púdica virgen ofendida / Que humillada descuella? / Se llama África, sí, África Bella! / Es la cuna del negro: esa es la patria / Del

13 Las cursivas son mías. Este caso de discriminación, así como las respuestas de varios periódicos de la comunidad afrodescendiente de Buenos Aires, son analizados en Geler 2010: 44-53. 
eterno proscrito que llora / Y lejos de sus lares / Eleva en patria extraña vOz sonora / Entonando el cantar de los pesares.

El poema continuaba narrando la forma como el verdugo blanco había destruido los lugares donde los cautivos africanos guardaban su memoria. Ante este acto cruel, el autor sentenciaba:

iAh! maldito, maldito por mil veces / seas, blanco sin fe; tu cruel memoria / sea eterno baldón para tu historia / que deshonre a los hijos de tus hijos, / y lleven en la frente / la mancha de la infamia que tú hicieras, / cual lleva el negro eternamente / las heridas del alma que le abrieras. / Maldito seas, sí, que hasta te arroje / de su seno la tierra, / porque fuiste su aborto y fue tu vida / signo de cruda y fratricida guerra.

Poemas como el de Thompson no fueron tan comunes entre los poetas afroargentinos. Quizá por ello, en un artículo publicado tres meses después de que el autor leyera su poema en un acto público, un crítico señaló que "en cuanto al argumento, es una composición llena de novedad e interés". El crítico también valoraba "la escrupulosidad que el poeta ha observado en la rima y el prudente uso que ha hecho de las imágenes que son las que representan la verdad filosófica de composición" (Cirio 2009: 128-133). Es posible que la fuerte crítica de Thompson no hubiera podido ser reconocida y difundida si no estuviera elaborada en un lenguaje poético, que permitía hablarle al poder dentro de sus propios cánones. Visto desde esta perspectiva, el "Canto al África" es una obra de gran originalidad y novedad en su época.

Los poemas exponen opiniones diversas sobre la posición de los afrodescendientes en la sociedad: así, mientras algunos condenan la esclavitud y son críticos hacia un sistema de clasificación social racializado y jerárquico, otros parecen asumir el blanqueamiento y la civilización en términos de las élites. De acuerdo con Geler, los intelectuales afroporteños concebían el "atraso" de su comunidad en el marco de representaciones revalidadas por ellos mismos en un "proceso de producción de hegemonía" (2008b: 182). Coincido con su interpretación y planteo que esta obra poética no es contrahegemónica, en la medida en que no logra cuestionar las 
representaciones hegemónicas, sino que se produce dentro de ellas. Esto no implica que no existieran voces de disenso y de resistencia ante la discriminación y el incumplimiento de la promesa de igualdad plasmada en las leyes posteriores al rosismo. No obstante, aunque esta poesía no fuera siempre transgresora ni contrahegemónica, revela las luchas de sus autores por incluirse en la literatura, en la historia y en la nación. Si, como pensaba Juan María Gutiérrez, la patria y la literatura estaban unidas de manera estrecha, la poesía afrodescendiente es un testimonio de cómo este grupo estaba pugnando por escribir su lugar dentro de la comunidad nacional.

BIBLIOGRAFÍA

AmANTE, AdRIANA. "La crítica como proyecto. Juan María Gutiérrez". Noe Jitrik (dir.). Historia crítica de la literatura argentina. Vol. 2. Buenos Aires: Emecé Editores, 2003. 161-190.

ANDREWS, GEORGE REID. Los afroargentinos de Buenos Aires. Buenos Aires: Ediciones de La Flor, 1989.

CIRIO, NORBERTO PABLO. Tinta negra en el gris del ayer: los afroporteños a través de sus periódicos entre 1873 y 1882. Buenos Aires: Editorial Teseo, 2009.

CREHAN, KATE. Gramsci, cultura y antropología. Barcelona: Bellaterra, 2002. CONSTITUCIONES ARGENTINAS. COMPILACIÓN HISTÓRICA Y ANÁLISIS DOCTRINARIO. Buenos Aires: Ministerio de Justicia y Derechos Humanos de la Nación, 2015.

Del Campo, Estanislao. Camila o la virtud triunfante. Buenos Aires: Imprenta de la Revista, 1856.

Di Meglio, GABRIEL. "La mazorca y el orden rosista". Prohistoria XII. 12 (2008): 69-90.

Echeverría, EsTEBAn. "El Matadero". Obras completas de D. Esteban Echeverría. Tomo V. Juan María Gutiérrez compilador. Buenos Aires: Imprenta y Librerías de Mayo, 1874. 209-242. 
GELER, LEA. Andares negros, caminos blancos. Afroporteños, estado y nación. Argentina a fines del siglo XIX. Rosario: Prohistoria Ediciones/ TEIAA, Universidad de Barcelona, 2010.

"'Marcando lentamente la obra de nuestra reorganización': intelectuales subalternos afroporteños y la construcción del estado nacional argentino a finales del siglo XIX". Mónica Mauri Martínez y Eugenia Rodríguez Blanco (coords.). Intelectuales, mediadores y antropólogos. La traducción y la reinterpretación de lo global en lo local. San Sebastián: Ankulegi, 2008b. 171-185.

¿"Otros" argentinos? Afrodescendientes porteños y la construcción de la nación argentina entre 1873 y 1882. Tesis de doctorado. Barcelona: Universitat de Barcelona, 2008.

González Bernaldo, Pilar. Civilidad y política en los orígenes de la nación argentina. Las sociabilidades en Buenos Aires, 1829-1862. Buenos Aires: FCE, 2000.

LEWIS, MARVIN. Afro-Argentine Discourse: Another Dimension of the Black Diaspora. Columbia: University of Missouri Press, 1996.

Mansilla de García, Eduarda. Cuentos. Buenos Aires: Imprenta de la República, 1880.

Manso de Noronha, Juana P. Los misterios del Plata. Buenos Aires: Imprenta Los Mellizos, 1899.

Mármol, José. Amalia. Tomos I y II. Leipzig: F.A. Brockhausl, 1877.

Molina, HeBe BEATRIZ. Como crecen los hongos: la novela argentina entre 1838 y 1872. Buenos Aires: Teseo, 2011.

NAVASCUÉS, JAVIER DE. "Estereotipo y afrodescendientes en la narrativa romántica argentina (Barbará, Manso, Gorriti)". Robert Folger y José Elías Gutiérrez (eds.), La mirada del otro en la literatura hispánica. Zurich: Lit Verlag, 2017. 171-194.

PALTI, ELÍAS. El momento romántico. Nación, historia y lenguajes políticos en la Argentina del siglo XIX. Buenos Aires: Eudeba/Universidad de Buenos Aires, 2009.

PÉRez Vejo, TomÁs. "Extranjeros interiores y exteriores: la raza en la construcción nacional mexicana”. Pablo Yankelevich (ed.). Inmigración y 
racismo: contribuciones a la bistoria de los extranjeros en México.

México: El Colegio de México, 2015. 89-124.

SÁBATO, HILDA. Pueblo y política: la construcción de la Argentina moderna. Buenos Aires: Capital Intelectual, 2010.

Salvatore, Ricardo. "Integral outsiders. Afro-Argentines in the era of Juan Manuel de Rosas and Beyond". Darién J. Davis (ed.). Beyond Slavery. The Multilayered Legacy of Africans in Latin America and the Caribbean, Lanham (Maryland, EU): Rowman and Littlefield, 2007. 57-80.

Sarmiento, Domingo Faustino. Facundo o Civilización y Barbarie. SI: Ediciones El Aleph, 1999.

SOLOMIANSKI, ALEJANDRO "Argentina y negritud: desde la otredad radicalizada hacia discursos más igualitarios". Cuadernos de Literatura XIX. 38 (2015): 99-118.

SOMMER, DoRIS. Ficciones fundacionales. Las novelas nacionales de América Latina. Bogotá: FCE, 2004.

PUBLICACIONES PERIÓDICAS

La Broma, año 1, época 5, 22 de agosto de 1878.

La Broma, año 1, época 5, núm. 12, 2 de octubre de 1879.

La Broma, año 1, época 5, núm. 22, 11 de diciembre de 1879.

La Broma, año 1, época 5, núm. 28, 24 de enero de 1880.

La Broma, año 1, época 5, núm. 33, 21 de marzo de 1880.

La Broma, año 1, época 6, núm. 7, 3 de febrero de 1881.

La Broma, año 1, época 6, núm. 28, 7 de julio de 1881.

La Broma, año 1, época 6, núm. 30, 23 de julio de 1881.

La Broma, año 2, época 6, núm. 78, 28 de julio de 1882. 